\title{
Leadership \& Professional Development: The Delicate Dance of Yes and No
}

\author{
Sherine Salib, MD, MRCP, FACP* , Anupama M Kapadia, MD
}

Department of Internal Medicine, Dell Medical School, The University of Texas at Austin, Austin, Texas.

"Success starts with saying yes. Saying no maintains it."

-Anonymous

Y ou have just received an opportunity that seems worthwhile. However, you already have a lot on your plate. What do you do? The balance of when to say "yes" and when to say "no" to opportunities, projects, and collaborations is often challenging, especially for busy clinicians. There is a trend, with good basis, to encourage individuals to say "no" more often. While there is much to be said for that, many good opportunities can be missed that way. As Amy Poehler put it, "Saying 'yes' doesn't mean I don't know how to say no."

So how does one arrive at a good balance?

\section{DEFINE GOALS AT EACH STAGE OF YOUR CAREER}

Most importantly, figure out who you are, what you want your "brand" to be and where you envision your career going. This is likely the most difficult step. Start with a roadmap and recalibrate as your career unfolds. Early in your career, seek breadth rather than depth.

As your career progresses, the "yes-no" balance may shift. We recommend you say "yes" frequently early on. Be open to opportunities that come up, even if they do not perfectly align with your goals. Explore opportunities beyond the limits of your job description. After all, opportunities beget more opportunities. Consider "stretch opportunities." If you are offered an opportunity that you may not have $100 \%$ of the skills for-and is, therefore, a "stretch" — but which aligns with your career goals, do not turn it down. Consider saying "yes" and learn on the job. A mentor or coach can help you navigate these decisions.

\section{CONSIDER THE MANY REASONS TO SAY "YES" OR "NO"}

Sometimes, it is important to say "yes" as part of being a "good citizen" in your department. Examples include mento-

"Corresponding Author: Sherine Salib, MD, MRCP, FACP;

Email: Sherine.Salib@austin.utexas.edu; Twitter: @DrSherineSalib.

Received: September 8, 2020; Revised: October 6, 2020;

Accepted: October 15, 2020

(c) 2021 Society of Hospital Medicine DOI 10.12788/jhm.3550 ring learners, serving on a safety committee, teaching student lectures, or coaching a colleague. Often it is possible to align service with career goals.

Another consideration is the benefit of networking: developing alliances and building bridges. In addition to the service or productivity that come with projects or collaborations, these can be powerful networking opportunities. Networking broadly, both within and beyond your field of practice and within and outside your institution, is an important way to create "bonding capital" and "bridging capital," ie, relationships based on your commonalities and relationships built across differences, respectively.

Remember, when you say "yes," you must deliver: every time, on time, and with excellence. When saying "yes" to more opportunities starts to impact your ability to deliver for what you have already committed to, it is time to say "no." This will help you maintain balance, avoid burnout, and stay focused.

\section{CONSIDER IMPACT VS EFFORT}

When juggling a busy schedule, consider effort vs impact. There are many low-effort opportunities that have relatively high impact. For instance, as a junior faculty member interested in medical education, participating in a grading committee is low effort but can help you understand the process, connect you with educational leaders, and open doors to future opportunities. An effective strategy may be to incorporate a combination of low-effort and high-effort activities at any one time, while considering the impact of each, to help maintain balance. The effort-vs-impact balance may shift as you grow in your career.

\section{CONCLUSION}

Know where you are going, explore the opportunities that may get you there, and recalibrate often. The path to success is typically a circuitous one, so enjoy the journey and give it your all every step of the way.

\section{Disclosures: The authors have nothing to disclose.}

\section{Reference}

1. Clark D. Start networking with people outside your industry. Harvard Bus Rev. October 20, 2016. Accessed December 11, 2020. https://hbr.org/2016/10/ start-networking-with-people-outside-your-industry 